\title{
DIREITOS HUMANOS E EMPRESAS \\ TRANSNACIONAIS: REFLEXÕES SOBRE PODER E RESISTÊNCIA
}

HUMAN RIGHTS AND TRANSNATIONAL

CORPORATIONS: FROM THE RELATIONS BETWEEN

POWER AND RESISTANCE

RESUMO: A partir do pensamento de Michel Foucault sobre relações de poder, estratégia, dispositivo, objetivase com esse artigo apresentar uma análise sobre a ausência de instrumentos que responsabilizem corporações transnacionais por violações de direitos humanos na ordem internacional. Através de pesquisa bibliográfica, constata-se que, apesar de que os grupos que controlam essas empresas exerçam poder de classe, há resistências. Verifica-se que, desde a década de 1970, o tema está incluído na agenda das Nações Unidas, e uma série de propostas foram apresentadas no debate sobre a responsabilização por violações de direitos humanos. Os resultados indicam a possibilidade de estabelecimento de um tratado vinculante sobre o tema, que exemplifica a luta constante nas relações de poder no globo.
ABSTRACT: Based on Michel Foucault's thinking on power relations, strategy, and device, this article aims to present an analysis of the absence of instruments that hold transnational corporations accountable for human rights violations in the international order. Through bibliographic research, it is observed that, although the groups that control these companies exercise class power, there are resistances. Since the 1970s, the issue has been on the United Nations agenda, and a number of proposals have been put forward in the debate on accountability for human rights violations. The results indicate the possibility of establishing a binding treaty on the subject, which exemplifies the constant struggle in the relations of power in the globe.

Palavras-chave: Relações de poder. Direitos humanos. Keywords: Power relations. Human rights. Business. Empresas.

\footnotetext{
${ }^{1}$ Doutoranda em Direitos Humanos pela Universidade Federal do Pará em missão de estudos na Pontifícia Universidade Católica do Rio de Janeiro, via acordo PROCAD-CAPES (2018). Possui mestrado em Direito pela Universidade Federal de Santa Catarina - UFSC (2015), área Direito e Relações Internacionais, e graduação em Direito pela Universidade Federal do Pará (2012). Atualmente é pesquisadora da Clínica de Direitos Humanos da Amazônia Universidade Federal do Pará, área Direitos Humanos e Empresas.
} 


\section{INTRODUÇÃO}

Como condições para o desenvolvimento de um pensamento crítico, Michel Foucault (1926-1984) propôs alguns critérios de análise para tratar problemas. Primeiramente, estabelecer as "necessidades conceituais" que sempre devem estar implicadas nas condições históricas que propiciam a conceituação, em segundo lugar, observar o tipo de realidade com a qual estamos lidando (FOUCAULT, 1995, p. 232).

Nesse sentido, com aportes do pensamento de Michel Foucault sobre relações de poder, estratégia, dispositivo, objetiva-se com esse artigo apresentar uma análise sobre uma das consequências sociais da globalização, a ausência de instrumentos que responsabilizem corporações transnacionais por violações de direitos humanos.

Para definir "poder", Foucault (1995, p. 240) esclarece que é necessário distinguir, primeiramente, aquele que exercemos sobre as coisas e que dá a capacidade de modificálas, utilizá-las, consumi-las ou destruí-las, um poder que remete a aptidões diretamente inscritas no corpo ou mediatizadas por dispositivos instrumentais.

Nesse caso, poder é "capacidade" de colocar em jogo relações entre indivíduos ou entre grupos. Se tratarmos do poder das leis, das instituições ou das ideologias, se falamos de estruturas ou de mecanismos de poder, é apenas na medida em que supomos que 'alguns' exercem um poder sobre os outros (FOUCAULT, 1995, p. 240). Assim, o termo "poder" designa relações entre "parceiros", um conjunto de ações que se induzem e se respondem umas às outras, isto é, um modo de ação de alguns sobre outros. Essas relações, sejam elas de cima para baixo ou de baixo para cima, devem ser apreendidas por meio das estratégias que as "coordenam", através dos "dispositivos".

O estudo das consequências sociais da globalização implica no destaque ao papel que empresas transnacionais passam a exercer em todo o mundo, a partir das políticas neoliberais dos anos 1980, que lhe permitiram impor domínio e monopólio sobre serviços essenciais e recursos naturais em praticamente todas as esferas, controlando a maioria dos setores estratégicos da economia mundial, sendo que algumas delas passam a exibir poder econômico superior ao valor do produto interno bruto (PIB) de alguns países. 
Na gestão dos riscos envolvidos nestas operações empresarias invariavelmente identificam-se violações aos direitos humanos internacionalmente reconhecidos. No mesmo cenário, intensificam-se processos de resistência de movimentos sociais e da sociedade civil no âmbito de organismos internacionais em prol da responsabilização de instituições financeiras e corporações por violações aos direitos humanos.

Assim, neste artigo, em um primeiro tópico apresentaremos reflexões sobre relações de poder e resistência, a partir da contribuição teórica de Michel Foucault para as ciências sociais, para em seguida nos aprofundarmos na análise da questão do Estado e do poder no neoliberalismo, a partir do estudo das tentativas de regulamentação de empresas transnacionais com relação às violações de direitos humanos no âmbito das Nações Unidas.

\section{RELAÇÕES DE PODER E RESISTÊNCIA}

No estudo das relações de poder e resistência, Michel Foucault apresenta uma contribuição essencial a partir da noção sobre dispositivos, que seriam estratégias de relações de forças sustentando tipos de saber, e sustentadas por eles (1994, p. 300). Isto é, são discursos, instituições, organizações arquitetônicas, decisões regulamentares, leis, etc; elementos discursivos e não discursivos que coordenam estratégias e relações de poder de grupos e indivíduos. Conforme Deluchey (2016, p. 189), a estratégia pode ser relacionada com a luta de classes.

Nesse sentido, se procurarmos a gênese de um dispositivo, esta pode ser encontrada na identificação da estratégia que o funda (DELUCHEY, 2016, p. 179).

Afinal, podemos resumir o que seria a gênese, o processo de construção de um dispositivo normativo. Primeiro, de forma mais inconsciente ou contingente de que consciente ou intencional, prevalece em um determinado campo de práticas, instituições e saberes certo objetivo estratégico que vai contribuir na refundação das funções, das práticas e das estratégias individuais e coletivas dos atores sociais interessados. A ação desses atores individuais e coletivos vai criar uma rede estratégica que, à medida de sua consolidação, vai se transformar em dispositivo normativo por meio de dois processos: uma sobredeterminação funcional, que vai servir de grade referencial para a transformação dos saberes, práticas e instituições que interessam na perspectiva da estratégia pré-definida, e um perpétuo preenchimento estratégico que vai resultar da ação múltipla e nem sempre conjunta dos atores do dispositivo, e das transformações estratégicas que podem ocorrer no decorrer do tempo (DELUCHEY, 2016, p. 182). 
Foucault (1995, p. 248) denomina como "estratégia de poder" o conjunto dos meios operados para fazer funcionar ou para manter um dispositivo de poder, que constituem modos de ação sobre a ação possível, eventual, suposta dos outros. Isto é, decifrando as estratégias, entendemos os mecanismos utilizados nas relações de poder.

A dominação é uma estrutura global de poder cujas ramificações e consequências podemos, às vezes, encontrar, até na trama mais tênue da sociedade; porém, e ao mesmo tempo, é uma situação estratégica mais ou menos adquirida e solidificada num conjunto histórico de longa data entre adversários. Pode perfeitamente acontecer que um falo de dominação seja apenas a transcrição de um dos mecanismos de poder de uma relação de confronto e de suas consequências (uma estrutura política derivada de uma invasão); também pode ocorrer que uma relação de luta entre dois adversários seja o efeito do desenvolvimento das relações de poder com os conflitos e as clivagens que ela encadeia. Porém, o que toma a dominação de um grupo, de uma casta ou de uma classe, e as resistências ou as revoltas às quais ela se opõe um fenômeno central na história das sociedades é o fato de manifestarem, numa forma global e maciça, na escala do corpo social inteiro, a integração das relações de poder com as relações estratégicas e seus efeitos de encadeamento recíproco (FOUCAULT, 1995, p. 249).

Nesse sentido, constata-se a relação entre relações de poder e estratégias de confronto, uma vez que toda relação de poder implica, pelo menos de modo virtual, uma estratégia de luta, sem que para tanto venham a se superpor, a perder sua especificidade e finalmente a se confundir (FOUCAULT, 1995, p. 248). Por isto, a estratégia é provavelmente o mais importante componente do dispositivo, porque este reina na estruturação da rede formada por esses elementos (DELUCHEY, 2016, p. 179).

Foucault (1995, p. 243) destaca que poder não é da ordem do consentimento, não é, em si mesmo, renúncia, liberdade ou transferência de direito, salvo exceções, ele não é, em sua própria natureza, a manifestação de um consenso. Nesse sentido, as relações de poder tem um caráter próximo à violência, que age sobre um corpo, sobre as coisas; ela força, ela submete, ela quebra, ela destrói.

No entanto, as relações de poder não fecham todas as possibilidades, ao contrário, articulam-se sobre dois elementos que Ihe são indispensáveis: que "o outro" seja inteiramente reconhecido e mantido até o fim como o sujeito de ação; e que se abra, diante da relação de poder, todo um campo de respostas, reações, efeitos, invenções possíveis (FOUCAULT, 1995, p. 243). Assim, sobre o exercício do poder: 
ele é um conjunto de ações sobre ações possíveis, operando sobre o campo de possibilidade onde se inscreve o comportamento dos sujeitos ativos; ele incita, induz, desvia, facilita ou torna mais difícil, amplia ou limita, toma mais ou menos provável; no limite, ele coage ou impede absolutamente, mas é sempre uma maneira de agir sobre um ou vários sujeitos ativos, e o quanto eles agem ou são suscetíveis de agir. Uma ação sobre ações (FOUCAULT, 1995, p. 243).

O exercício do poder consistiria em "conduzir condutas" e em ordenar a probabilidade, entendo conduta tanto como o ato de "conduzir" os outros, segundo mecanismos de coerção mais ou menos estritos, e a maneira de se comportar num campo mais ou menos aberto de possibilidades (FOUCAULT, 1995, p. 243-244). O autor continua:

quando definimos o exercício do poder como um modo de ação sobre as ações dos outros, quando as caracterizamos pelo "governo" dos homens, uns pelos outros - no sentido mais extenso da palavra, incluímos um elemento importante: a liberdade. O poder só se exerce sobre "sujeitos livres", enquanto "livres" entendendo-se por isso sujeitos individuais ou coletivos que têm diante de si um campo de possibilidade onde diversas condutas, diversas reações e diversos modos de comportamento podem acontecer (FOUCAULT, 1995, p. 244).

Assim, para Michel Foucault (1995, p. 232), a liberdade aparecerá como condição de existência do poder, de forma que a relação de poder e a insubmissão da liberdade não podem, então, ser separadas. Foucault destaca que quando os sujeitos humanos são colocados em relações de produção, sempre é colocado em relações de poder muito complexas.

Para o autor, existem três tipos de lutas, mesmo quando estão misturadas, uma delas na maior parte do tempo, prevalece: contra as formas de dominação, seja étnica, social ou religiosa; contra as formas de exploração que separam os indivíduos daquilo que eles produzem; ou contra aquilo que liga o indivíduo a si mesmo e o submete, deste modo, aos outros (FOUCAULT, 1995, p. 235).

Se, no século XIX, a luta contra a exploração surgiu em primeiro plano, atualmente, a luta contra as formas de sujeição estão se tornando cada vez mais importantes, a despeito de as lutas contra as formas de dominação e exploração não terem desaparecido (FOUCAULT, 1995, p. 236). Esse processo poderia ser analisado como uma grande crise da experiência ocidental da subjetividade.

Para Deleuze (1992, p. 220), essa crise tem relação com a crise generalizada de todos os meios de confinamento, seja prisão, fábrica, escola, família, as antigas disciplinas, 
quando passam a ser substituídas por sociedades disciplinares. Nesse cenário, o controle seria o novo monstro, quando o objetivo é controlar até o ar livre, de forma que os mecanismos de controle rivalizam com os mais duros confinamentos, através da empresa e do neoliberalismo.

Enquanto os confinamentos são moldes, os controles são uma modulação, como uma moldagem auto-deformante, que mudasse continuamente a cada instante, ou como uma peneira cujas malhas mudassem de um ponto para outro (DELEUZE, 1992, p. 221).

O melhor exemplo seria o salário, na sociedade de controle a empresa é uma alma, a empresa se esforça mais profundamente em impor uma modulação para cada salário, num estado de perpetua metaestabilidade. Assim, a fabrica constitui os indivíduos em um só corpo, para a dupla vantagem do patronato que vigiava cada elemento na massa, e dos sindicatos que o mobilizavam a massa de resistência, enquanto a empresa introduz o tempo todo uma rivalidade inexpiável como sã emulação, excelente motivação que contrapõe os indivíduos entre si e atravessa cada um, divindo-o em si mesmo (DELEUZE, 1992, p. 221).

Assim, na empresa, não se está mais diante do par massa-individuo, os indivíduos tornaram-se individuais, divisíveis, e as massas tornaram-se amostras, dados, mercados ou bancos (DELEUZE, 1992, p. 222).

\section{ESTADO E RELAÇÕES DE PODER}

Dessa forma, para compreendermos a ação dos dispositivos nos atores sociais, não apenas devem ser estudados os dispositivos normativos em si, a exemplo das normas jurídicas, políticas públicas, práticas governamentais, especialmente judiciárias, mas também os impactos dos mesmos na dimensão intraindividual, isto é, dentro de cada indivíduo que vai interiorizando e naturalizando os comandos sociais e os referenciais destes dispositivos e acaba se autorregulando, se autocontrolando e, finalmente, se moldando seguindo a lógica dos referidos dispositivos (DELUCHEY, 2016, p. 184).

Nesta dimensão, Deluchey (2016, p. 184) salienta que o processo normativo do dispositivo aparenta-se a um processo normalizador, muito mais de que um processo 
normatizador, que se torna ainda mais agravado no neoliberalismo, conforme veremos no tópico subsequente.

Podemos dizer que todos os tipos de sujeição são fenômenos derivados, que são meras consequências de outros processos econômicos e sociais, tais como forças de produção, luta de classe e estruturas ideológicas que determinam a forma de subjetividade (FOUCAULT, 1995, p. 236). No entanto, não se resumem apenas a esses processos, mantêm relações complexas e circulares com outras variantes.

Tomando os exemplos de uma serie de oposições que se desenvolveram nos últimos anos, tais como o poder dos homens sobre mulheres, psiquiatra sobre o doente mental, etc.; o autor define o que elas têm em comum: são lutas transversais, ou seja, não são limitadas a um país, não são confinadas a uma forma politica e econômica particular de governo; os objetivos das lutas são os efeitos de poder enquanto tal; são lutas imediatas, objetivam o inimigo imediato e não a solução para os problemas do futuro; questionam o estatuto do individuo, afirmam o direito de ser diferente mas atacam tudo aquilo que quebra a relação com os outros, a vida comunitária, que separa o individuo, que o liga a própria identidade de um modo coercitivo, o "governo da individualização"; são oposição aos efeitos do poder relacionados ao saber, luta contra os privilégios do saber, oposição ao segredo e suas relações com o poder; recusam a abstrações, do estado de violência econômico e ideológico, que ignora quem somos individualmente e que determina quem somos (FOUCAULT, 1995, p. 234-235).

Em síntese, para Foucault (1995, p. 235) o objetivo dessas lutas seria atacar a técnica, uma forma de poder.

Esta forma de poder aplica-se à vida cotidiana imediata que categoriza o indivíduo, marca-o com sua própria individualidade, liga-o à sua própria identidade, impõe-lhe uma lei de verdade, que devemos reconhecer e que os outros têm que reconhecer nele. É uma forma de poder que faz dos indivíduos sujeitos. Há dois significados para a palavra sujeito: sujeito a alguém pelo controle e dependência. e preso à sua própria identidade por uma consciência ou autoconhecimento. Ambos sugerem uma forma de poder que subjuga e toma sujeito a.

Ao se debruçar sobre a questão de o que legitima o poder, Foucault defronta-se com a análise do Estado. Isto é, a razão pela qual este tipo de luta tende a prevalecer em 
nossa sociedade deve-se ao fato de que, desde o século XVI, essa nova forma política de poder se desenvolveu de modo contínuo.

Foucault (1995, p. 236) destaca que, na maior parte dos estudos teóricos, o Estado é considerado um tipo de poder político que ignora os indivíduos, ocupando-se apenas com os interesses da totalidade ou, de uma classe ou um grupo dentre os cidadãos.

No entanto, o autor enfatiza o fato de que o poder do Estado é uma forma de poder tanto individualizante quanto totalizadora, que pode ser considerada uma das razões da sua força, já que, anteriormente, não havia nas mesmas estruturas políticas uma combinação tão astuciosa das técnicas de individualização e dos procedimentos de totalização (FOUCAULT, 1995, p. 236).

O que diferencia o Estado moderno ocidental é que este integrou, numa nova forma política, uma antiga tecnologia de poder originada nas instituições cristãs. Podemos chamar esta tecnologia de poder pastoral ${ }^{2}$.

Esta forma de poder é orientada para a salvação (por oposição ao poder político). É oblativa (por oposição ao princípio da soberania); é individualizante (por oposição ao poder jurídico); e co-extensiva à vida e constitui seu prolongamento; está ligada à produção da verdade - a verdade do próprio indivíduo (FOUCAULT, 1995, p. 237).

Nesse sentido, para o autor, o "Estado moderno" não deve ser considerado como uma entidade que se desenvolveu acima dos indivíduos, ignorando o que eles são e até mesmo sua própria existência, mas, ao contrário, como uma estrutura muito sofisticada, na qual os indivíduos podem ser integrados sob uma condição: que a esta individualidade se atribuísse uma nova forma, submetendo-a a um conjunto de modelos muito específicos (FOUCAULT, 1995, p. 237). Foucault considera o Estado moderno como a matriz moderna da individualização.

\footnotetext{
${ }^{2} \mathrm{O}$ cristianismo é a única religião a se organizar como uma Igreja. E como tal, postula o princípio de que certos indivíduos podem, por sua qualidade religiosa, servir a outros não como príncipes, magistrados. profetas, adivinhos, benfeitores e educadores, mas como pastores. Contudo, esta palavra designa uma forma muito específica de poder: 1) É uma forma de poder cujo objetivo final é assegurar a salvação individual no outro mundo; 2) O poder pastoral não é apenas uma forma de poder que comanda; deve também estar preparado para se sacrificar pela vida e pela salvação do rebanho. Portanto, é diferente do poder real que exige um sacrifício de seus súditos para salvar o trono; 3 ) É uma forma de poder que não cuida apenas da comunidade como um todo, mas de cada indivíduo em particular, durante toda a sua vida. 4) Finalmente, esta forma de poder não pode ser exercida sem o conhecimento da mente das pessoas, sem explorar suas almas, sem fazer-lhes revelar os seus segredos mais íntimos. Implica um saber da consciência e a capacidade de dirigi-la; (FOUCAULT, 1995, p. 237).
} 
A conclusão seria que o problema político, ético, social e filosófico de nossos dias não consiste em tentar liberar o indivíduo do Estado nem das instituições do Estado, porém nos liberarmos tanto do Estado quanto do tipo de individualização que a ele se liga. Temos que promover novas formas de subjetividade através da recusa deste tipo de individualidade que nos foi imposto há vários séculos (FOUCAULT, 1995, p. 238).

Se nos confrontamos com o que o autor chama de duas doenças do poder, facismo e estalinismo, ele defende que o que precisamos é uma economia do poder, isto é, assim como o papel da filosofia é prevenir a razão de ultrapassar os limites daquilo que é dado na experiência; essa economia deveria partir da analise das formas de resistência contra as diferentes formas de poder, usando esta resistência como um catalisador químico de modo a esclarecer as relações de poder, localizar sua posição, descobrir seu ponto de aplicação e os métodos utilizados, isto é analisar as relações de poder através do antagonismo das estratégias (FOUCAULT, 1995, p. 234).

\section{PODER NO NEOLIBERALISMO: AS EMPRESAS TRANSNACIONAIS}

O Estado é o mediador e o recurso de ultima instancia legitimador da integração das sociedades no capitalismo global (MENDES, 2016). Nesse cenário, destacam-se as empresas transnacionais, que são aquelas que operam a escala internacional, vinculadas entre si mediante uma complexa rede de relações institucionais, de propriedade, de produção, comerciais, administrativo-financeiras e tecnológicas, com uma sede matriz e com uma grande estratégia comum (NEUMANN, 2007, p. 66).

A tendência a instalar operações de empresas em distintos países e continentes se acelerou com o fim da Segunda Guerra Mundial, em um processo que foi liderado por empresas cuja sede central se encontrava nos Estados Unidos. Das 500 maiores empresas, 222 vinham dos Estados Unidos, 130 da União Europeia, 71 do Japão, enquanto 8 eram da América Latina. Neste grupo reduzido de países que possuem matrizes de transnacionais é que são tomadas as principais decisões da economia mundial.

A partir da década de 1990, a histórica econômica da América Latina é marcada pela influência das políticas que seguiram ao Consenso de Washington, documento apresentado pelo Institute for International Economics em 1989, com propostas de reformas que já vinham sendo aplicadas em alguns países da América Latina e que eram 
consenso entre os membros do Congresso e governo estadunidense, tecnocratas das instituições financeiras internacionais, agências econômicas do governo norte-americano e o Federal Reserve Board (BANDEIRA, 2002, p. 35).

Este conjunto de políticas macroeconômicas previa um amplo programa de reformas estruturais dirigidas aos países da periferia (OLIVEIRA, 2011, p. 146), com recomendações de que o Estado se retirasse da economia, seja como empresário ou como regulador das transações domésticas e internacionais, a fim de que toda a América Latina se submetesse às forças do mercado.

A adoção de tais medidas constituiria condição fundamental para que estes Estados pudessem renegociar a dívida externa e receber qualquer recurso das agências financeiras internacionais, como o Bando Mundial e Fundo Monetário Internacional. A ratificação da proposta neoliberal tornava-se condição para negociar qualquer cooperação financeira externa, bilateral ou multilateral, de forma que os países teriam que sujeitar suas respectivas políticas econômicas e decisões de investimentos à fiscalização internacional, por meio das condicionalidades.

Os principais países latino-americanos ficaram diante do seguinte dilema: ou declaravam moratória ou se submetiam aos órgãos intergovernamentais de regulação financeira. A quase totalidade dos governos acabou optando pela segunda alternativa (SINGER, 1996, p. 164).

Assim, esta década foi marcada pela expansão do padrão de controle societário destas empresas, com base no compartilhamento do controle entre sócios nacionais e estrangeiros, a formação de alianças estratégicas entre grupos nacionais, a participação no movimento de desestatizações promovido em setores estratégicos em âmbito mundial.

Com efeito, a partir de então, registrou-se a maior quantidade de entrada de investimentos estrangeiros do último século na América Latina, a maior parte destinada a compra de empresas. As transnacionais participaram diretamente da privatização de grandes empresas de serviços públicos e na compra de bancos. Assim, as políticas neoliberais serviram para construir um quadro político, econômico, jurídico e cultural, em escala global, do qual as grandes corporações foram as principais beneficiárias (RAMIRO; GONZALES, 2013). 
Nesse sentido, constata-se que o neoliberalismo não se trata apenas de uma ideologia, um tipo de política econômica; tornou-se um sistema normativo que ampliou sua influencia ao mundo inteiro, estendendo a lógica do capital a todas as relações sociais e formas de vida (DARDOT; LAVAL, 2016, p. 06). Nesse sentido, Dardot e Laval (2016, p. 272-273) verificam a continuidade da intervenção do Estado, e passam a analisar seus objetivos e métodos.

Muito frequentemente esquecemos que o neoliberalismo não procura tanto a retirada do Estado e a ampliação dos domínios da acumulação do capital quanto a transformação da ação pública, tornando o Estado uma esfera que também é regida por normas de concorrência e submetida a exigências de eficácia semelhantes àquelas as que se sujeitam as empresas privavas. O Estado foi reestruturado de duas maneiras que tendemos a confundir: de fora, com privatizações maciças de empresas públicas que põem fim ao "Estado produtor", mas também de dentro, com a instauração de um Estado avaliador e regulador que mobiliza novos instrumentos de poder e, com eles, estrutura novas relações entre governo e sujeitos sociais.

Em todo o mundo, empresas transnacionais e os Estados nacionais se envolveram em complexas relações de negociação, de forma que estas passam a ser não só organizações econômicas, como também políticas, com o potencial de influenciar nas políticas tanto do país matriz como do governo anfitrião (NEUMANN, 2007, p. 66). De modo geral, as transnacionais são um dos principais motores do desenvolvimento capitalista, exercendo papel central na exploração e transferência das riquezas do Sul global para o Norte (GARCIA, 2009, p. 11).

Nesse contexto de esquecimento da política e de opulência da esfera econômica, marcado pela ampliação do poderio das corporações empresariais e conglomerados financeiros, argumenta-se, aqui, que as relações centro-periferia sofreram alterações, sendo hoje mais adequado vislumbrar a existência de um regime de dominação exercido por essas corporações de forma policêntrica e gerando multiperiferias. Assim, as novas relações centro-periferia não estariam mais vinculadas a posições geográficas estanques, expressas na figura dos Estados territoriais; ao contrário disso, derivariam da ação econômica de corporações transnacionais e conglomerados financeiros organizados em redes, estruturados territorialmente, apoiados por um Estado-nacional de origem, sendo policêntricos e engendrando multiperiferias. A posição de centro deixaria de ser exercida por um ou mais estados nacionais. Romper-se-ia, assim, com a perspectiva de uma relação centro-periferia geográfica, transitando para um centro-periferia ubíquo, levado a cabo por corporações transnacionais, compostas por capitais trasnfronteiriços que atuam em todas as partes do mundo (ASSIS, 2014, p. 620). 
O Estado emerge como incompleto e contraditório nas suas práticas e políticas, atuando de forma oscilante e imprevisível entre um Estado predador e um Estado protetor (MENDES, 2016, p. 65).

Robinson (2004) propõe ampliar a ideia de hegemonia para além de uma forma de dominação social inextricavelmente associada ao Estado. Ao contrário disso, sugere que grupos sociais e classes compostas no cenário das relações interestatais passam a exercer a hegemonia, operando de forma transnacional e utilizando outros arranjos e formas institucionais.

O avanço transfronteiriço dos capitais tem desencadeado uma apropriação privada dos recursos naturais territorializados em países tidos como atrasados; uma parte considerável desses recursos vem se transformando, quase que inevitavelmente, em propriedade privada de empresas transnacionais (LEIVA, 2009).

Invariavelmente, ignora-se que auditorias, relatórios, diretivas, do FMI, OMC, OCDE, etc. e mesmos dos sistemas internacionais de direitos humanos, as quais os Estados signatários de convenções internacionais em tese deveriam "se curvar", contam com partes diretamente interessadas nisso.

Dardot e Laval (2016, p. 283-284) ressaltam que as grandes instituições internacionais criadas após a Segunda Guerra mundial constituem os principais vetores de imposição da nova ordem neoliberal, através da qual o Estado é entendido como parceiro dos interesses oligopolistas na guerra econômica mundial, ordenando as sociedades de acordo com as exigências da concorrência mundial e das finanças globais.

Com efeito, um dos principais obstáculos para atuar contra as ações ilícitas das transnacionais são as ameaças concretas ou temores de que a empresa translade suas instalações para outro país com menores restrições, colocando em risco os postos de trabalho e geração de impostos. Nesse sentido, para Deluchey (2016, p. 185), a arte neoliberal de governar busca normalizar as pessoas a partir de dispositivos reguladores.

Por sua vez, segundo a arte neoliberal de governar, busca-se normalizar as pessoas a partir de dispositivos reguladores. O que importa, na sociedade neoliberal, é definir o normal e o anormal, e deduzir daí as normas e instituições necessárias à instauração de uma governamentalidade, uma arte de governar que vai passar não apenas pelo Estado, mas também vai penetrar as relações interindividuais e intraindividuais, por meio do controle recíproco e do autocontrole dos indivíduos. 
Podemos afirmar que os grupos que controlam as corporações transnacionais tornaram-se classe dominante a partir do desenvolvimento de estratégias de classe. No entanto, conforme o apresentado nos tópicos anteriores, não existe um sujeito histórico coletivo detentor de um poder de classe que impõe a sua dominação de cima para baixo sobre um sujeito histórico sem que haja resistências.

O destaque cada vez maior às obrigações em direitos humanos de atores não estatais, o reconhecimento crescente de direitos econômicos e sociais, e campanhas fora do âmbito das Nações Unidas contra o potencial destrutivo de projetos de desenvolvimento de grandes corporações, que impulsionaram o surgimento de novas formas de responsabilização de instituições financeiras por danos ambientais e sociais; são descritos por Patricia Feeney $(2009$, p. 175) como os principais motivos para que a partir dos anos 70, o tema de direitos humanos e empresas passasse a integrar a agenda internacional.

Assim, paulatinamente, empresas transnacionais passaram a ser reconhecidas como importantes violadores de direitos humanos, com destaque a sua atuação no Sul Global, no entanto, a luta pela sua responsabilização enfrenta diversos obstáculos ante a onda de globalização dominante, que pouco espaço concede às perspectivas críticas ao capital, assim como ao marco institucional de debate e negociação sobre o tema no âmbito das Nações Unidas, a qual sobre com a captura corporativa (ROLAND, 2017, p. 22).

No Brasil, pesquisa desenvolvida pelo Consórcio Latino-americano de PósGraduação em Direitos Humanos aponta diversos problemas com relação ao cumprimento dos direitos humanos nestas empresas no Brasil, como: presença de trabalho análogo à escravidão; trabalho infantil; déficits no acesso à justiça e informação; violações do direito à liberdade sindical, entre outros; e comprometendo mais ainda este cenário, problemas sérios de articulação institucional no combate à estas práticas e de fiscalização pelos órgãos responsáveis ${ }^{3}$.

\footnotetext{
${ }^{3}$ Resultados preliminares de pesquisa ainda em andamento realizada pelo Consórcio Latino-Americano de Pósgraduação em Direitos Humanos, com apoio da Clínica de Direitos Humanos da Amazônia, Universidade Federal do Pará, e Fundação Ford. Para saber mais, ver: http://www.consorciodh.ufpa.br/>.
} 
Nesse contexto, houveram diversas tentativas de Estados e da sociedade civil para elaborar parâmetros globais de responsabilização de empresas envolvidas em violações de direitos humanos, a partir do desenvolvimento da contraposição de dois projetos: um eminentemente voluntarista, que se coaduna com a responsabilidade social empresarial; e outro, que busca o estabelecimento de um instrumento vinculante que considere o cumprimento dos direitos humanos como condicionantes do empreendimento.

Em 1973, foi criada a Comissão da ONU sobre Empresas Transnacionais com a missão de investigar o impacto das empresas transnacionais, bem como aumentar a capacidade de negociação dos países em que elas operam (JERBI, 2009). Desta iniciativa, foi apresentado o primeiro projeto de estabelecer diretrizes sociais e ambientais para as corporações, o Código de Conduta da ONU sobre TNCS, rejeitado por governos influentes do Norte, onde muitas estão sediadas (FEENEY, 2009, p. 176).

Na mesma época, a Organização para Cooperação e Desenvolvimento Econômico (OECD, na sigla oficial), lança as Diretrizes da OECD para Empreendimentos Multinacionais, de 1976, documento que não continha nenhuma referência aos direitos humanos e visava proteger os investidores internacionais.

Em 1977, a Organização Internacional do Trabalho adotou a Declaração Tripartita de Princípios relativos a Empreendimentos Multinacionais e Política Social, que demanda que as empresas respeitem convenções internacionais de direitos humanos.

Um contexto de maior mobilização, facilitado pelas novas alianças constituídas entre ativistas de direitos humanos, ambientalistas, e outros grupos, propiciou o surgimento de três outras iniciativas, cada uma com seus parâmetros e mecanismos: o Pacto Global da ONU (1999), iniciativa voluntária que tem como objetivo a promoção de direitos humanos dentro das práticas empresariais; a revisão ampla das Diretrizes da OECD (2000), que passou a mencionar expressamente a Declaração Universal dos Direitos Humanos; e as Normas sobre Responsabilidades de direitos humanos das Empresas Transnacionais e outros empreendimentos privados da ONU (2003), outra tentativa principiológica de responsabilização de empresas que terminou rechaçada dentro da organização. 
Nesse cenário, em 2005, a Comissão de Direitos Humanos da ONU solicitou que o Secretário-Geral indicasse um Relator Especial sobre o tema de direitos humanos e empresas, nomeando o Professor John Ruggie como Representante Especial sobre Empresas e Direitos Humanos (RESG, na sigla original). Dois anos depois, Ruggie apresentou um relatório de mapeamento sobre o tema dos direitos humanos e empresas, reconhecendo que a expansão dos mercados e o alcance transnacional da atividade empresarial não coincidiu com uma expansão de igual magnitude da proteção de indivíduos e comunidades contra violações de direitos humanos envolvendo empresas (NAÇÕES UNIDAS, 2007, par. 3).

Em seu relatório de 2008, formula o marco conceitual "Proteger, Respeitar e Remediar: Um Marco sobre Empresas e Direitos Humanos", composto por três partes: Estados possuem o dever de proteger contra violações de direitos humanos cometidas por terceiros, incluindo empresas, por meio de políticas, normas, bem como processos judiciais adequados; empresas possuem a responsabilidade de respeitar normas de direitos humanos, o que, segundo o RESG, implica, essencialmente, controlar os riscos de causar danos aos direitos humanos, buscando, em última instância, evitar tais danos; e vítimas de direitos humanos devem ter maior acesso a remédios efetivos, incluindo mecanismos nãojudiciais de denúncia (NAÇÕES UNIDAS, 2008).

Este marco normativo amplo apresentado pelo RESG foi bem recepcionado por associações empresariais, governos e por muitas organizações da sociedade civil (FEENEY, 2007, p. 183). Assim, estendem por mais três anos o mandato do RESG, com a missão de operacionalizar o marco apresentado.

Em 2011, o Conselho dos Direitos Humanos da ONU adota os Princípios Orientadores sobre Empresas e Direitos Humanos, também conhecidos como Princípios Ruggie, que oferecem parâmetros globais para se prevenir e tratar de impactos negativos de direitos humanos relacionados com atividades empresariais. No mesmo ano, também foi criado o Grupo de Trabalho sobre Empresas e Direitos Humanos da ONU (GT), cujo mandato inclui o desenvolvimento da implementação dos Princípios Orientadores.

Os Princípios Orientadores não estabelecem novas obrigações ou desenvolvem um quadro conceitual diferente: simplesmente desenvolvem os princípios estabelecidos no 
quadro de 2008. Assim, são "compromissos políticos" feitos pelos Estados no âmbito das Nações Unidas sobre orientações, recomendações e normas para a conduta empresarial responsável. Estas disposições têm como característica comum a intenção de exigir que as empresas respeitem standards sociais e ambientais ${ }^{4}$, porém não são previstos mecanismos de sanção pelo não cumprimento.

A partir de 2014, o Grupo de Trabalho de Empresas e Direitos Humanos passa a recomendar que cada país elabore um Plano Nacional de Ação com respeito aos princípios orientadores. Em 2016, a União Europeia adquire papel de destaque no incentivo à implementação destes planos na América Latina.

Apesar da abertura de novos fóruns de discussão, verifica-se que todo este arcabouço de princípios estabelecidos pela ONU, OIT, OECD, ou em nível privado, constatase que mecanismos como a Responsabilidade Social Corporativa são insuficientes frente ao poder das transnacionais (UGALDE, 2013, p. 174) e não foram capazes de modificar o cenário de impunidade ante a violações de direitos humanos.

Assim, a necessidade de algum instrumento vinculante internacional que permita que os três pilares de Ruggie (respeitar, proteger e remediar) se apliquem com algum tipo de obrigatoriedade complementar a oferecida pela jurisdição nacional ainda permanece como uma demanda da sociedade civil organizada.

Em 2014, foi dado início outra tentativa de regulamentação de empresas dentro da ONU. Em 26 de setembro, durante a 26a sessão do Conselho de Direitos Humanos da ONU foram aprovadas duas resoluções sobre o tema de empresas e direitos humanos, uma que garante a continuidade ao enfoque dos princípios orientadores e busca aprofundar sua implementação, enquanto a outra estabeleceu a criação de um Grupo de Trabalho encarregado de elaborar um projeto de instrumento vinculante sobre Direitos Humanos e Empresas.

\footnotetext{
${ }^{4}$ Nesse sentido, entre os princípios orientadores, destacamos a due diligence ou devida diligência, ligada à gestão de riscos, e como a empresa está organizada internamente (políticas, mecanismos e relações externas) para "reduzir o risco" de violar os direitos humanos ou contribuir para violações cometidas por outros. Assim concebida, o conceito de due diligence é construído sobre as práticas existentes no mundo dos negócios na área de gestão de riscos financeiros e de mercado, e é parte de algumas correntes teóricas políticas e legais. Mas diligência sobre os direitos humanos não pode se confundir a gestão de riscos para a empresa a partir de uma perspectiva de diligência normal de negócios, uma vez que estes riscos se referem aos direitos humanos das comunidades onde a empresa opera ou planeja operar (LÓPES-HURTADO, 2016, p. 51).
} 
Com efeito, as duas resoluções sobre o mesmo tema aprovadas simultaneamente, ainda que tenham o mesmo objetivo, possuem perspectiva e orientação diferenciadas. A aprovação da resolução 26/9, agora conhecida como "resolução do tratado", deu-se devido ao apoio direto de países como Equador, Bolívia e África do Sul.

A partir dos debates em torno deste Grupo, que já realizou três sessões, surge a possibilidade de reconhecimento das empresas transnacionais como sujeitos de direitos e deveres perante o Direito Internacional, passíveis, portanto, de responsabilização diante da violação de Direitos Humanos (HOMA, 2015, p. 6). Assim, indivíduos prejudicados poderiam exigir diretamente das empresas a reparação de forma independente da atuação dos Estados, que agiriam como intermediários neste processo, permitindo a quebra da distância na relação entre as vítimas de violações de direitos humanos e as empresas violadoras.

Nesse sentido, retomamos Deluchey (2016, p. 191) e a análise das estratégias e das relações de poder, se exigem reciprocidade, significa que as relações de poder são marcadas por uma luta constante para ampliar ou reduzir os efeitos de poder, visando o sucesso ou o fracasso das estratégias de cada ator, como a luta pela responsabilização das corporações transnacionais por violações aos direitos humanos.

\section{CONSIDERAÇÕES FINAIS}

Com aportes principalmente do pensamento de Michel Foucault sobre relações de poder, estratégia, dispositivo, objetivou-se com esse artigo apresentar uma análise sobre uma das consequências sociais da globalização, a ausência de instrumentos que responsabilizem corporações transnacionais por violações de direitos humanos.

A partir do estudo sobre a gênese dos dispositivos, constatamos sua relação com as estratégias para o estabelecimento de relações de poder, entendendo que essas relações nunca são consensuais, e sempre envolvem resistências e lutas. Nesse sentido, o enfoque das organizações internacionais por mecanismos de cumprimento voluntário com relação a obrigações de direitos humanos para empresas transnacionais pode indicar a presença de uma estratégia de sucesso que busca evitar a celebração de um instrumento vinculante sobre o tema. 
Com efeito, a análise sobre a expansão do domínio das corporações transnacionais pelo mundo, com destaque para a América Latina, após o Consenso de Washington, demonstrou o avanço do neoliberalismo como sistema normativo que estendeu a lógica do capital a todas as relações sociais. Assim, com a expansão das políticas econômicas neoliberais na América Latina, verifica-se que com a entrada de investimentos e acionistas internacionais, mercantilizou-se setores básicos da vida das pessoas, através de privatizações massivas, incluindo serviços públicos essenciais para o gozo dos direitos humanos e coesão social.

Entretanto, constatou-se que, apesar das estratégias terem conferido aos grupos que controlam essas empresas poder de classe, há resistências. Em âmbito internacional, desde a década de 1970, o tema dos "Direitos Humanos e Empresas" está incluído na agenda das Nações Unidas. A possibilidade de estabelecimento de um tratado vinculante sobre o tema exemplifica a luta constante nas relações de poder.

Nesse sentido, sob a perspectiva dos estudos das relações de poder, da teoria crítica das relações internacionais e dos direitos humanos, verifica-se que o debate sobre a impunidade das empresas transnacionais e sobre a captura corporativa do Estado e da democracia se tornam urgentes para os processos de luta pela efetivação de direitos humanos.

\section{REFERÊNCIAS}

ASSIS, Wendell Fischer Teixeira. Do colonialismo à colonialidade: expropriação territorial na periferia do capitalismo. CRH, Salvador, v. 27, n. 72, p. 613-627, set./dez. 2014.

BANDEIRA, Luiz Alberto Muniz. As políticas neoliberais e a crise na América do Sul. Revista Brasileira de Política Internacional, v. 45, n. 2, p. 135-146, 2002.

DARDOT, Pierre; LAVAL, Christian. A nova razão do mundo: ensaio sobre a sociedade neoliberal. Trad. Mariana Echalar. 1. ed. São Paulo: Boitempo, 2016.

DELEUZE, G. "Post-Scriptum sobre as sociedades de controle". In: Conversações, 19721990, São Paulo: Ed. 34, 1992 [1990]. p. 219-226.

DELUCHEY, J. F. Sobre Estratégias e Dispositivos Normativos em Foucault: 1.Considerações de Método. Revista da Faculdade de Direito da UFG, v. 40, p. 175-196, 2016. 
FEENEY, Patricia. A Luta por Responsabilidade das Empresas no Âmbito das Nações Unidas e o Futuro da Agenda de Advocacy. SUR - Revista Internacional de Direitos Humanos, v. 6, n. 11, p. 175-191, 2009.

FOUCAULT (M.) O sujeito e o poder. In: DREYFUS, H. ; RABINOW, P. Michel Foucault, uma trajetória filosófica: para além do estruturalismo e da hermenêutica. Rio de Janeiro: Forense Universitária, 1995, p. 231-249.

GARCIA, Ana Seggioro. Empresas transnacionais brasileiras: dupla frente de luta. In: Instituto Rosa LuxemburgStiftung (Org.). Empresas transnacionais brasileiras na América Latina: um debate necessário. 1. ed. São Paulo Expressão Popular, 2009.

LEIVA, Orlando Caputo. A economia mundial e a América Latina no início do século XXI. In: MARTINS, Carlos Eduardo; SOTELO VALENCIA, Adrian (Org.). A América Latina e os desafios da globalização: ensaios dedicados a Ruy Mauro Marini. São Paulo: Boitempo, 2009.

MENDES, José Manuel. A dignidade das pertenças e os limites do neoliberalismo: estrofesfes, capitalismo, Estado e vítima. Sociologias, Porto Alegre, ano 18, n. 43, p. 58-86, set./dez. 2016.

NAÇÕES UNIDAS. Comission on Human Rights. Human rights and transnational corporations and other business enterprises. U.N. Doc. E/CN.4/RES/2005/69. 20 Apr. 2005. Disponível em: <http://ap.ohchr.org/documents/E/CHR/resolutions/E-CN_4-RES2005-69.doc>. Acesso em: 29 dez. 2016.

NAÇÕES UNIDAS. Human Rights Council. Business and Human Rights: Mapping International Standards of Responsibility and Accountability for Corporate Acts. U.N. Doc. A/HRC/4/035. 2007. Disponível em: <http://www.businesshumanrights.org/Documents/RESG-report-Human-Rights-Council-19-Feb-2007.pdf>. Acesso em: 29 dez. 2016.

NAÇÕES UNIDAS. Human Rights Council. Protect, Respect and Remedy: A Framework for Business and Human Rights, Report of the Special Representative of the Secretary-General on the issue of human rights and transnational corporations and other business enterprises, John Ruggie. U.N. Doc. A/HRC/8/5. 7 Apr. 2008. Disponível em: <http://www.reports-and-materials.org/Ruggie-report-7-Apr-2008.pdf>. Acesso em: 29 dez. 2016.

NEUMANN, Raul Allard. Las empresas multinacionales en la globalización. Relaciones con los Estados. Estudios Internacionales, n. 158, p. 59-99, 2007. Disponível em: <https://core.ac.uk/download/pdf/46533788.pdf>. Acesso em: 03 mar. 2017.

OLIVEIRA, Rodrigo Ferreira. A contra-reforma do Estado no Brasil: uma análise crítica. Revista Urutágua - UEM, n. 24, p. 132-146, 2011.

RAMIRO, Pedro; GONZALES, Erica. Empresas transnacionales: impactos y resistências. Ecologista, n. 77, jun. 2013.

ROBINSON, William I. What empire? Whose hegemony? The transnationalization of capital and the gramscian critique of "statolatry". In: ANNUAL CONFERENCE OF INTERNATIONAL STUDIES ASSOCIATION, Montreal, mar. 2004. 
SINGER, Paul. Perspectivas de desenvolvimento da América Latina. Novos Estudos, CEBRAP, n. 44, p. 133-164, mar. 1996.

UGALDE, Koldo. Los Acuerdos Marco Internacionales (AMIs) ¿Oportunidad para reequilibrar poder frente a las empresas transnacionales (ETNs)? Una visión desde la EU. In: Juan Hernández Zubizarreta et al. (Org.). Empresas transnacionales en América Latina. Análisis y propuestas del movimiento social y sindical. Bilbao: Universidad del País Basco/Hegoa/ Observatorio de Multinacionales en América Latina Bakea ta Duintasuna / Asociación Paz con Dignidad, 2013. p. 173-185.

VIEIRA, Flávia do Amaral. Direitos humanos e empresas transnacionais: reflexões sobre poder e resistência. RBSD - Revista Brasileira de Sociologia do Direito, v. 6, n. 1, p. 106-125, jan./abr. 2019. 